ISSN 25980580

Bioscientia Medicina Volume 4, Issue 1, Page No: 48-57

Available online : www.bioscmed.com

Bio Sc Med 4(1) :48-57

\title{
Evaluation of CTEV Management in Children's Walking Ability Assessed By "Bangla" Club Foot Tool Score System
}

\author{
Nur Rachmat Lubis ${ }^{1}$, Irfannuddin Irfannuddin ${ }^{1 \#}$, Febian Aji Wicaksono ${ }^{1}$ \\ ${ }^{1}$ Faculty of Medicine, Universitas Sriwijaya, Palembang, Indonesia \\ ${ }^{\#}$ Correspondent author E-mail: irfan.md@unsri.ac.id
}

Received : October $25^{\text {th }} 2019$

Accepted : December $26^{\text {th }} 2019$

\begin{abstract}
Background

Congenital talipes equinovarus (CTEV) or clubfoot is a congenital deformity that involves an abnormal position of the calcaneonaviculare complex. "Bangla clubfoot tool score system" is an assessment that indicates the effectiveness of CTEV management. The purpose of this study was to evaluate the management of CTEV on children's ability to walk as assessed by the Bangla clubfoot tool score system.

Methods

A cross sectional study was conducted at the Hospital Dr. Mohammad Hoesin Palembang. There were 24 CTEV patients who received CTEV management before the age of 3 years and were not associated with a neurological disorder. A comparison of the average total Bangla clubfoot score tool system was analyzed by assessing parental satisfaction, walking ability and clinical examination.
\end{abstract}

\section{Results}

The majority of CTEV patients were women (58.3\%) with and mostly being treated before 1 year old (79.2\%). The most types of CTEV were bilateral $(70.8 \%)$, and most of them performed surgery (66.7\%). Assessment with the Bangla clubfoot tool system shows that the level of parental satisfaction is sufficient, gait is good, but physical foot examination is poor $(20 \%)$. The score is influenced by age at first therapy and compliance using the brace.

Conclusion

Parents must continue to support their children to undergo integrated management after therapy to maintain their walking ability.

Keywords: Bangla clubfoot tool score system, CTEV, therapy

\section{Introduction}

Congenital talipes equinovarus (CTEV) or clubfoot is a congenital deformity that involves abnormal positions of the calcaneonaviculare complex (os calcaneus and os naviculare). ${ }^{1}$ This component of deformity is often understood by mnemonic CAVE (cavus, adductus, varus, equinus). The incidence of CTEV ranges from 1-2 for every 1,000 live births with a case ratio 
ISSN 25980580

between boys and girls of 2:1.,3 The incidence of CTEV varies in several countries, in the United States 2.29 for every 1000 births, in the Caucasian race 1.6: 1000 births; in the Oriental race 0.57: 1000 births; in Maori 6.5-7.5: 1000 births; in Chinese 0.35: 1000 births; in the Polynesian race 6.81: 1000 births; and in Malaysian 1.3: 1000 births. Incidence will increase if there is a family history of CTEV. The possibility of CTEV if there is a family history of about 1:35 cases, and about 1: $3(33 \%)$ if the child is born identical twins. ${ }^{4}$ About $20 \%$ of cases of CTEV are associated with congenital (spina bifida and cerebral palsy) and other neuromuscular abnormalities. ${ }^{5.6}$

The etiology of CTEV is not fully understood. CTEV is generally an isolated birth defect and is thought to be idiopathic, although it sometimes presents with myelodysplasia, arthrogryposis, or multiple congenital abnormalities. ${ }^{6}$ Early recognition and treatment of clubfoot is very important because the golden period of therapy is three weeks after birth. At less than three weeks, the ligaments in the legs are still flexible so they can be manipulated. The management of CTEV depends on the patient's age and also according to Pirani's classification. Non-operative therapy using the Ponseti method, which includes strapping and tapping techniques, manipulation and serial casting, as well as functional therapy, is a gold standard in the management of CTEV. ${ }^{7,8}$ This non-operative therapy is recommended to be carried out as soon as possible after birth so that the foot can be corrected properly. ${ }^{9}$

Integrated clubfoot management programs are mostly carried out in developing countries. The Bangladesh Clubfoot Project, Walk for Life (WFL) is a nongovernmental organization established since 2009. ${ }^{7.10}$ WFL is a sustainable clubfoot management program in Bangladesh, and indicates success in implementing CTEV management in poor countries. This institution developed a grading system known as the Bangla clubfoot tool score system (BCTS) ${ }^{7,11}$ At present there are no scientific data on the success rate of CTEV management in children's walking ability as measured by the Bangla clubfoot tool score system in Indonesia. Evaluation of the management of CTEV with the Ponseti procedure and surgery is necessary.

\section{Methods}

This study was a cross sectional approach on children's walking ability after getting CTEV management. Interviews and clinical examinations were conducted at the orthopedic surgery clinic 
ISSN 25980580

at the Mohammad Hoesin Hospital in Palembang and /or visited their homes. The inclusion criteria were CTEV patients who received management before the age of 3 years. CTEV patients who were associated with a neurological abnormality such as spina bifida, arthrogryposis, muscular dystrophy, and spinal muscular atrophy were excluded. Subjects that met the inclusion criteria were assessed using the BCTS system. This scoring consists of the level of parental satisfaction with the quality of the child's limbs, observation of the child's motor skills, and clinical assessment of the foot and ankle joint morphology (Table 3). For parental satisfaction, the score is given a value of one (1) if it is as expected, a score of zero (0) if unsure, and a value of minus one (-1) if it is not as expected. For motor skills, given a value of 1 if able to be independent, a value of 0 if with support, and a value of (-1) if unable at all. For clinical examination, given a value of 1 if the position of valgus / dorsiflexion, a value of 0 if perpendicular and a value of -1 if plantarflection. The maximum value of the scoring system is eleven (11) and if all the results are bad then the minimum value is minus eleven (-11) (Table 1). The results of the assessment are divided into categories, namely very good, good, sufficient, and poor. ${ }^{7}$ The data collected was entered into the computer. Data is presented in tabular form, the relationship between the results of BCTS with the type of management was analyzed using the chi square test.

Table 1. Bangla clubfoot tool score ${ }^{11}$

\begin{tabular}{cccccc}
\hline \multirow{2}{*}{ A. Parental Rating } & Yes & Don't know & No & $\begin{array}{c}\text { Mean scores } \\
(\%)\end{array}$ & Rating \\
& +1 & 0 & -1 & & $\#$ \\
\hline
\end{tabular}

1. Happy with with child's feet

2. Recommend to others

3. Does child play with others?

4. Does child wear shoes of choice?

5 . Does child have no pain

Parental rating subscore (-/5)

\begin{tabular}{lccccc}
\hline B. Gait Assessment & Yes & $\begin{array}{c}\text { Not fully/ } \\
\text { with } \\
\text { assistance }\end{array}$ & No & $\begin{array}{c}\text { Mean scores } \\
(\%)\end{array}$ & Rating \\
\cline { 2 - 6 } & +1 & 0 & -1 & \\
\hline 6. Squatting & \multicolumn{5}{l}{} \\
\hline
\end{tabular}


7. Walking

8. Running

9, Up/down steps

Gait assessment sub score (-/4)

\section{C.Clinical Examination}

10. Left heel position

Right heel position

11. Left ankle range

Right ankle range

Clinical examination sub score (-/2)

Score Categori

Very good 11

Good 9-10

Fair $\quad 7-8$

Poor $\quad<7$

\section{Results}

The number of subjects who met the inclusion criteria was 24 subjects and female were higher number. Most subjects had bilateral CTEV with a family history of clubfoot deformity reported in 2 cases. The age at which CTEV was first treated, mostly as children aged $\leq 1$ year. All CTEV patients performed Ponseti before the age of 3 years, but not all of them followed standard procedures. A total of 8 subjects was treated with conservative procedures, and most of the rest followed the achilles tendon lightning surgery.

Table 2. General characteristics of subjects

$$
\text { Variables n (\%) }
$$

\section{Gender}

Male

Female

$10(41.7)$

14 (58.3) 


\begin{tabular}{lc}
\hline The age at which CTEV was performed & \\
$0-1$ years old & $13(79.2)$ \\
$>1$-2 years old & $5(16.7)$ \\
$>2-3$ years old & $6(4.2)$ \\
\hline Types of CTEV & $7(29.2)$ \\
Unilateral & $17(70.8)$ \\
Bilateral & \\
Treatments after the Ponseti procedure & $8(33.3)$ \\
Conservative & $16(66.7)$ \\
Operative &
\end{tabular}

The results of the assessment with the Bangla clubfoot tool score system in table 3 and table 4. The description indicated that the level of parent satisfaction was sufficient at $62.8 \%$. Functionally, most children can walk, run, squat and manage their footsteps independently, although there were some children who still need assistance. Clinical assessment of the heel indicated a relapse into the varus position, and the ankle showed the area of motion that only reached the planti-grade.

Table 3. Category of Bangla Club Foot Tool Score

\begin{tabular}{lc}
\hline Bangla Club Foot Tool Score & $\mathrm{n}(\%)$ \\
\hline Verygood (11) & $1(4.2)$ \\
Good (9-10) & $6(25.0)$ \\
Fair $(7-8)$ & $10(41.7)$ \\
Poor $(<7)$ & $7(29.2)$ \\
\hline
\end{tabular}

Table 4. The description of Bangla Clubfoot Tool Score among subjects

\begin{tabular}{lccc}
\hline A. Parental Rating & Yes & Don't know & No \\
& $\mathbf{+ 1}$ & $\mathbf{0}$ & $\mathbf{- 1}$ \\
\hline 1. Happy with with child's feet & 18 & 6 & 0 \\
2. Recommend to others & 22 & 2 & 0 \\
3. Does child play with others ? & 23 & 1 & 0 \\
4. Does child wear shoes of choice ? & 10 & 14 & 0
\end{tabular}


5. Does child have no pain

B. Gait Assessment

5

Yes
1

\section{Not fully/} with No assistance

\begin{tabular}{lccc} 
& $\mathbf{+ 1}$ & $\mathbf{0}$ & $\mathbf{- 1}$ \\
\hline 6. Squatting & 21 & 1 & 2 \\
7. Walking & 22 & 1 & 1 \\
8. Running & 16 & 7 & 1 \\
9, Up/down steps & 16 & 7 & 1 \\
\hline C.Clinical Examination & Valgus & Lurus & Varus \\
\hline 10. Left heel position & $\mathbf{+ 1}$ & $\mathbf{0}$ & $\mathbf{- 1}$ \\
\hline \multicolumn{1}{c}{ Right heel position } & 10 & 9 & 5 \\
& 9 & 11 & 4 \\
\hline \multicolumn{1}{c}{ Right ankle range } & $\mathbf{0}$ & $\mathbf{0 / 9 0}$ degrees & dorsifleksi \\
& dorsiflextion & $\mathbf{0}$ & $\mathbf{- 1}$ \\
\hline 11. Left ankle range & $\mathbf{+ 1}$ & 7 & 3 \\
\hline
\end{tabular}

In cross-table analysis, the BCTS was recode into 2 categories, fair/good and poor. BCTS results are not influenced by gender, type of CTEV, serial casting compliance, and operative or conservative management. Treatment carried out at an earlier age and adherence to using brace, increase the chances for a better prognosis.

Table 5. Factors influence on Bangla Clubfoot Tool Score

\begin{tabular}{|c|c|c|c|}
\hline \multirow{2}{*}{ Category } & \multicolumn{3}{|c|}{ Bangla Clubfoot Tool Score } \\
\hline & $\begin{array}{l}\text { Fair } \\
\text { Good }\end{array}$ & Poor & $\mathrm{P}$ \\
\hline \multicolumn{4}{|l|}{ Gender } \\
\hline Male & $7(70.0)$ & $3(30.0)$ & $* *>0.05$ \\
\hline Female & $10(71.4)$ & $4(28.6)$ & \\
\hline \multicolumn{4}{|c|}{ Age on first treatment } \\
\hline $0-1$ years old & $12(92.3)$ & $1(7.7)$ & \\
\hline $1-2$ years old & $2(40.0)$ & $3(60.0)$ & $*<0.05$ \\
\hline
\end{tabular}


$>2$ years old

Types of CTEV

Unilateral

Bilateral

Compliance with serial casting manipulation

Obey $(>5 \mathrm{x}$ regularly)

Not obey

Compliance using Denis Browne bar-shoe

Obey ( $>3$ month continuously)

Not obey

Type of treatment

Achiles tendo lengthening/tenotomy

Conservative
$3(50.0) \quad 3(50.0)$

$14(77.8) \quad 4(22.2)$

$3(50.0) \quad 3(50.0)$

$11(78.6) \quad 3(21.4) \quad * *>0.05$

$6(60.0) \quad 4(40.0)$

$13(86.7) \quad 2(13.3) \quad * *<0.05$

$4(44.4) \quad 5(55.6)$

$13(81.2) \quad 3(18.8)$

$* *>0.05$

*Chi square test; **Fisher exact test

\section{Discussion}

This study found that the CTEV number of girls was relatively the same as that of boys. The Bangla clubfoot tool score between male and female patients also showed no difference. The results of this study are not much different from the study of Harnett et al in 2011 in which the same percentage was obtained between male and female patients. ${ }^{12}$ Gender is not significantly associated with congenital clubfoot. ${ }^{14}$

Although not statistically significant, better BCTS results are more for patients with bilateral deformity. This may be due to patient compliance to maintain the brace. The unilateral brace is generally custom made which may be associated with less comfort than the bilateral brace. ${ }^{15}$

In this study, the level of parental satisfaction was not good enough. This showed that parents did not expect more that the child can walk normally. The subjective element of parental assessment is aimed at satisfaction with therapy. In contrast to research conducted by Evans et al on the WFL program in Bangladesh, where parental satisfaction scores showed high scores. ${ }^{7,11}$ Parental support is needed to improve patient outcomes. Health workers need to explain to families and the community about clubfoot including its causes and treatment. Children's walking function will improve if the treatment is carried out in an integrated and continuous manner. Parents must be convinced that the cause of clubfoot is not a parent's fault. Parent's motivation, patience and consistency are needed for effective therapy. Parents always give reasons for not taking CTEV 
ISSN 25980580

therapy adequately. This is due to limited resources such as transportation costs, child care costs and availability of time due to life demands. (Evans) The government funding insurrance program for integrated management of CTEV may be able to reduce the burden on parents. In other cases, it is possible that parents have not understood enough about Ponseti therapy, especially regarding the use of special shoes (brace / Denis-Browne bar and shoes) that are being worn. ${ }^{7}$

Statistical analysis has shown that there was no difference in the classification of the Bangla clubfoot tool score between patients who have performed operative or conservative measures. Non-operative therapy using the Ponseti method, which includes strapping and tapping techniques, manipulation and serial casting, as well as functional therapy, is the gold standard in the management of CTEV. ${ }^{3,7}$ Ponseti manipulation combined with percutaneous tenotomy generally gives very good results. It's just that without followed by a good bracing, there would be a relapse of more than $80 \%$. Relapse will decrease to only $6 \%$ in families who were obedient in the bracing program. ${ }^{8}$ This study has proven that the use of brace has a good effect on improving the motion function of subjects. Obedient families are those who understand the method of managing CTEV and the importance of bracing. ${ }^{3}$ Parent education is needed so that the management of CTEV takes place optimally. Parents should be given the understanding that surgery alone is not enough to improve the function of the patient's movements.

\section{Conclusion}

Parents must continue to support their children to undergo integrated management after therapy to maintain their walking ability.

\section{References}

1. Winell, J.J., Davidson R.S.. 2016. Talipes Equinovarus (Clubfoot). Dalam: Kliegman, R.M., Stanton B.F., St Geme III J.W., Schor N.F. (Editor). Nelson textbook of Pediatrics, ed. 20, vol. (hal 3248-3250). Elsevier, Philadelphia 
ISSN 25980580

2. Halanski, M.A., Davison J.E., Huang J.C., Walker C.G., Walsh S.J., Crawford H.A.. 2010. Ponseti Method Compared with Surgical Treatment of Clubfoot. The Journal of Bone and Joint Surgery, 92-270-278

3. Ullah, Md. S., Ferdous K.M.N., Shahjahan Md., Sayed Sk. A. 2013. Management of Congenital Talipes Equinovarus (CTEV) by Ponseti Casting Technique in Neonates: Our Experience. Journal of Neonatal Surgery, 2(2):17

4. Nordin S, Aidura M, Razak S, Faisham WI. 2002. Controversies in Congenital Clubfoot : Literature Review. Malaysian Journal of Medical Sciences. Vol. 9, No. 1(34-40).

5. Siapkara, A., R. Duncan. 2007. Congenital Talipes Equinovarus: A Review of Current Management. The Journal of Bone and Joint Surgery, 89-B(8):995-999

6. Dobbs, M.B., Gurnett C.A.. 2009. Update on Clubfoot: Etiology and Treatment. Clinical Orthopaedics and Related Research, 467:1146-1153

7. Evans A.M., Chowdhury M.M.H., Kabir M.H., Rahman M.D. 2016. Walk for life - the National Clubfoot Project of Bangladesh: the four-year outcomes of 150 congenital clubfoot cases following Ponseti method. Journal of Foot and Ankle Research. 9:42

8. Staheli, L.. 2009. Clubfoot: Ponseti Method, ed. 3. Washington: Global Help

9. Ayana, B., Klungsøyr P.J.. 2014. Good Result after Ponseti Treatment for Neglected Congenital Clubfot in Ethiopia. Acta Orthopaedica, 85(6):641-645

10. Ford-Powell VA et al. 2013. The Bangladesh Clubfoot Project: The First 5000 Feet. J Pediatr Orthop. 33:e40-e44.

11. Evans AM, Perveen R, Ford-Powell VA, Barker S. 2014. The Bangla clubfoot tool: a repeatability study. Journal of Foot and Ankle Research. 7:27

12. Harnett, P., Freeman R., Harrison W.J., Brown L.C., Beckles V.. 2011. An Accelerated Ponseti Versus the Standard Ponseti Method. The Journal of Bone and Joint Surgery: A Prospective Randomized Controlled Trial, 93-B(3).

13. Hefti, Fritz, Bruner R., Freuler F., Hasler C., Jundt G.. 2007. Pediatric Orthopedics in Practice. New York: Springer-Verlag Berlin Heidelberg

14. Maranho, D. A. C., Volpon J.B.. 2011. Congenital Clubfoot. Acta Ortopédica Brasileira, 19(3):163-169 
ISSN 25980580

15. C Saetersdal, JM Fevang, LB Engessaeter. Inferior results with unilateral compared with bilateral brace in Ponseti-treated clubfeet. Journal of Children's Orthopaedics 